\title{
Addressing HCV Elimination Barriers in Italy: Healthcare Resource Utilization and Cost Impact Using 8 Weeks' Glecaprevir/Pibrentasvir Therapy
}

\author{
Massimo Andreoni - Giovanni Di Perri - Marcello Persico • \\ Andrea Marcellusi - Olivier Ethgen - Yuri Sanchez Gonzalez • \\ Mark Bondin · Zhenzhen Zhang • Antonella De Michina • \\ Rocco Cosimo Damiano Merolla · Antonio Craxì
}

Received: November 25, 2020 / Accepted: January 29, 2021 / Published online: March 3, 2021

(C) The Author(s) 2021

\section{ABSTRACT}

Introduction: In Italy, hepatitis C virus (HCV) elimination is achievable; however, barriers remain to achieving the World Health Organization's elimination targets, and have become more pronounced with the spread of COVID19. Glecaprevir/pibrentasvir $(\mathrm{G} / \mathrm{P})$ is a directacting antiviral therapy for HCV, approved for 8-week treatment in patients without cirrhosis, and with compensated cirrhosis (CC). Previously, 12 weeks of therapy was recommended for patients with CC. Shortened treatment may reduce the burden on healthcare resources, allowing more patients to be treated. This study

M. Andreoni $(\square)$

University of Tor Vergata, Rome, Italy

e-mail: andreoni@uniroma2.it

G. Di Perri

Department of Clinical Infectious Diseases,

University of Turin, Turin, Italy

M. Persico

Internal Medicine and Hepatology Unit,

Department of Medicine and Surgery "Scuola

Medica Salernitana", University of Salerno,

Baronissi, Italy

A. Marcellusi

Center for Economic and International Studies, Faculty of Economics, University of Tor Vergata, Rome, Italy presents the benefits that 8 -week vs 12 -week treatment with G/P may have in Italy.

Methods: A multicohort Markov model was used to assess the collective number of healthcare visits and time on treatment with 8-week vs 12-week G/P in the HCV-infected population of Italy from 2019 to 2030, using healthcare resource data from post-marketing observational studies of $\mathrm{G} / \mathrm{P}$. Increased treatment capacity and downstream clinical and economic benefits were also assessed assuming the reallocation of saved healthcare visits to treat more patients.

Results: Modeled outcomes showed that by 2030, 8-week treatment saved 27,006 years on therapy compared with 12 -week treatment, with 21,065 fewer hepatologist visits.

\section{O. Ethgen}

SERFAN Innovation, Namur, Belgium

O. Ethgen

Department of Public Health, Epidemiology and

Health Economics, University of Liège, Liège,

Belgium

Y. Sanchez Gonzalez · M. Bondin · Z. Zhang

AbbVie Inc, North Chicago, IL, USA

A. De Michina - R. C. D. Merolla

AbbVie S.R.L, Rome, Italy

A. Craxì

GI and Liver Unit, PROMISE, University of Palermo,

Palermo, Italy 
Reallocating these resources to treat more patients could increase capacity to treat 5064 (1.4\%) more patients with 8 weeks of $\mathrm{G} / \mathrm{P}$, all with CC. This increased treatment capacity would further avoid 2257 cases of end-stage liver disease, 893 liver-related deaths, and provide net savings to the healthcare system of nearly $€ 70$ million.

Conclusion: The modeled comparisons between 8- and 12-week treatment with G/P show that shorter treatment duration can lead to greater time and resource savings, both in terms of healthcare visits and downstream costs. These benefits have the potential to enable the treatment of more patients to overcome elimination barriers in Italy through programs aimed to engage and treat targeted HCV populations.

Keywords: Elimination; Glecaprevir/pibrentasvir; Hepatitis $C$ virus; Italy; Treatment duration

\section{Key Summary Points}

\section{Why carry out this study?}

The elimination of HCV infection in Italy is a possibility; however, barriers remain to achieving the WHO HCV elimination goal of 2030, as well as the expected disruption to elimination efforts due to COVID-19.

A shorter, 8-week treatment duration of G/P may help reduce the burden on healthcare resources and allow reallocation to increase treatment capacity for HCV.

This study presents the benefits to healthcare resources that 8-week vs 12-week treatment with glecaprevir/ pibrentasvir $(\mathrm{G} / \mathrm{P})$ may have in Italy.

\section{What was learned from the study?}

The resources saved through shortened G/P treatment would increase the capacity to treat by $5064(1.4 \%)$ more patients, avoid 2257 cases of end-stage liver disease, 893 liver-related deaths, and provide a net savings to the healthcare system of nearly $€ 70$ million.

Shorter treatment duration can lead to greater resource savings which has the potential to enable treatment of more patients and overcome elimination barriers in Italy.

\section{DIGITAL FEATURES}

This article is published with digital features, including a summary slide, to facilitate understanding of the article. To view digital features for this article go to https://doi.org/10.6084/ m9.figshare.13655654.

\section{INTRODUCTION}

Approximately 71 million people worldwide are chronically infected with hepatitis $\mathrm{C}$ virus (HCV) [1]. HCV is one of the leading causes of chronic liver disease worldwide, which can lead to life-threatening complications such as hepatic decompensation and hepatocellular carcinoma (HCC) [1, 2]. Since the availability of interferon (IFN)-free direct-acting antivirals (DAAs) in 2014, treatment options for hepatitis $\mathrm{C}$ have reduced in duration and become better tolerated and more effective (sustained virologic response [SVR] rates of greater than 95\%) than the previously available IFN-based therapies [3]. Glecaprevir/pibrentasvir $(\mathrm{G} / \mathrm{P})$ is a fixed dose, once-daily, all-oral combination DAA therapy approved to treat chronic HCV in patients without cirrhosis or with compensated cirrhosis [4, 5]. Previously, 12-week treatment with $\mathrm{G} / \mathrm{P}$ was recommended for treatmentnaïve patients with compensated cirrhosis and 8-week treatment was recommended for 
treatment-naïve patients without cirrhosis $[4,5]$. As a result of the data reported in the phase IIIb EXPEDITION-8 trial, which showed 8-week G/P treatment to be highly efficacious (with an SVR at post-treatment week 12 rate of 99.7\%) and well tolerated in patients with compensated cirrhosis, G/P has recently been approved in both the USA and Europe for 8-week treatment of all treatment-naïve patients, including those with compensated cirrhosis [4-6].

The World Health Organization (WHO) has set a goal to eliminate HCV as a major public health threat by 2030 [1]. This includes diagnosing $90 \%$ of individuals with HCV and initiating treatment in $80 \%$ of eligible patients [1]. However, many countries are not on track to meet this target [7]. The availability of pangenotypic, IFN-free DAA regimens for $\mathrm{HCV}$ treatment means HCV elimination is a realistic goal, but the estimated prevalence of $\mathrm{HCV}$ and number of undiagnosed patients remains high, often owing to a lack of screening and treatment, with only approximately $13 \%$ of patients thought to be aware of their HCV status and receiving treatment. The estimated year of $\mathrm{HCV}$ elimination in Italy is 2029 [8]; however, as a result of the impact of COVID-19, delays to achieving HCV elimination are expected, with models estimating increases in liver-related deaths and cancers [9]. In addition, Italy saw a loss of progress before the pandemic, with a $35 \%$ reduction in the annual number of patients who initiated treatment in 2019 compared to 2018 [10].

In Italy, prevalence of HCV is estimated to be $1 \%$ in total, with rates differing between age groups [11]. The national health service in Italy (Servizio Sanitario Nazionale, SSN) provides universal coverage to citizens and residents and allows unrestricted access to DAAs for individuals with $\mathrm{HCV}[12,13]$. HCV management is a significant burden on the SSN in Italy, with healthcare resource utilization (HCRU) increasing with advanced disease states, such as decompensated cirrhosis and HCC [14]. In patients who do not receive $\mathrm{HCV}$ treatment, the rate of disease progression is known to be higher compared with those who are treated, with untreated patients with $\mathrm{HCV}$ requiring extra healthcare resources, in particular hospitalizations [14]. A cost analysis of HCV management showed that in Italy, the mean healthcare cost associated with HCV infection was $€ 6022.7$ per patient [14]. Costs associated with patients with HCC and those who require liver transplants are estimated to be $€ 50$ million and $€ 48$ million annually, respectively [13].

A shorter 8-week treatment duration may reduce burden on healthcare resources and allow reallocation of these resources to treat additional patients. This is of increased importance given the recent impact of COVID-19 on healthcare resources and potential deprioritization of clinical resources and budget allocation for HCV therapy in patients with less advanced disease. This study aims to use real-world data in a Markov model to assess the potential clinical and economic benefits of 8 -week vs 12 -week $\mathrm{G} / \mathrm{P}$ treatment of individuals with HCV in Italy.

\section{METHODS}

\section{Study Model}

A previously published open multicohort Markov model was updated to assess the clinical and economic outcomes of treating the noncirrhotic and compensated cirrhotic HCV population in Italy with G/P for 8 vs 12 weeks from 2019 onwards with a screening program that diagnosed $90 \%$ of HCV infections by 2030 [15].

The data for the Italian population came from post-marketing observational studies (PMOS) of G/P [16-20]. Eligible patients were followed from treatment initiation until 12 weeks after the end of treatment (EOT) or until premature discontinuation. Patients were aged at least 18 years with HCV GT1-6 infection and received G/P at the treating physician's discretion according to local label, national or international recommendations, and/or local clinical practice. The PMOS studies were performed in accordance with the Helsinki Declaration of 1964, and its later amendments, and all patients provided informed consent to participate. HCRU and patient-reported outcomes were pooled and analyzed, with data collected from 18 January 2018 to 7 January 2019. HCRU 
was assessed using the total number of study visits with a healthcare provider per patient. Patients with HCV infection were eligible for the PMOS if they were receiving G/P according to local label, national or international recommendations, and/or local clinical practice. The HCRU and SVR analyses were performed on the core population with sufficient follow-up (CPSFU), defined as patients from the core population, excluding those who did not have an HCV RNA evaluation after post-treatment day 70 due to reasons not related to effectiveness or safety (lost to follow-up or unavailable HCV RNA data). Patients included in the CPSFU had one of the following: HCV RNA data after post-treatment day 70 (not included if the drug end date was unknown), virologic failure (on- treatment virologic failure or post-treatment relapse), discontinued the study because of an adverse event (AE), and had HCV RNA less than $50 \mathrm{IU} / \mathrm{mL}$ at the last measurement.

The model showed the progression of the diagnosed HCV population from 2019 to 2030, adding a cohort of newly diagnosed patients annually (Fig. 1). Data inputs included HCV natural history, treatment efficacy, epidemiologic data, and cost inputs (Table 1). Cost inputs were obtained from published literature and included healthcare costs associated with liverrelated complications (such as liver-related deaths, liver transplant, HCC, decompensated cirrhosis, and extrahepatic manifestations). The model calculated the collective number of healthcare visits and years on treatment for the

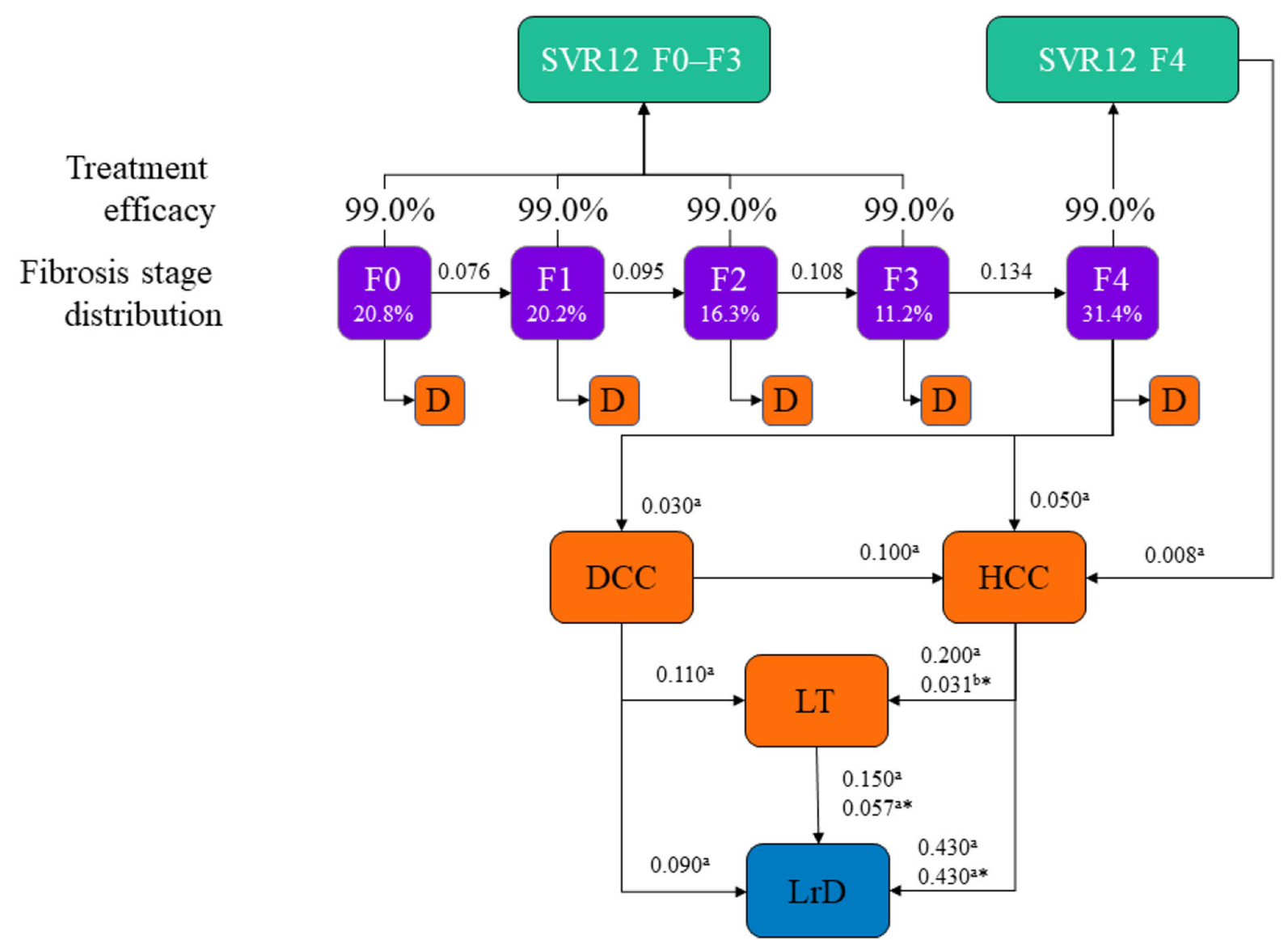

Fig. 1 Study design for model. Sources: ${ }^{a}$ Marcellusi PharmacoEconomics. 2019;37:255-266 (base case $=2017$ years); ${ }^{b}$ Rein et al. Clin Infect Dis. 2015;15:61:157-68. *Annual transition probability after the first year. D death,
DCC decompensated cirrhosis, F fibrosis, HCC hepatocellular carcinoma, LrD liver-related death, LT liver transplant, SVR12 sustained virologic response at posttreatment week 12 
Table 1 Data inputs ${ }^{\mathrm{a}}$

\begin{tabular}{|c|c|c|}
\hline Data input & Base & Source \\
\hline \multicolumn{3}{|l|}{ Prevalence 2019} \\
\hline $\begin{array}{l}\text { Prevalent cases in } \\
2019\end{array}$ & 410,775 & Kondili et al. Hepatology 2019;70(S1):P520 \\
\hline Fraction diagnosed & $60 \%$ & Assumption \\
\hline Average age (years) & 55.9 & Bayesian model \\
\hline \multicolumn{3}{|l|}{ Annual incidence } \\
\hline $\begin{array}{l}\text { Annual incident } \\
\text { cases }\end{array}$ & 3604 & Bayesian model \\
\hline Average age (years) & 55.9 & Bayesian model \\
\hline \multicolumn{3}{|l|}{ Costs } \\
\hline $\begin{array}{l}\text { Screening (cost per } \\
\text { patient) }\end{array}$ & $€ 9$ & $\begin{array}{l}\text { Cicchetti PharmacoEconomics-2011 Cicchetti et al. PharmacoEconomics-Italian } \\
\text { Research Article 2011;13(2):81-99 }\end{array}$ \\
\hline $\begin{array}{l}\text { Treatment } \\
\text { (8 weeks) }\end{array}$ & $€ 6000$ & Regione Emilia-Romagna Aggiornamento Luglio 2019 \\
\hline \multicolumn{3}{|l|}{ Medical (annual costs) } \\
\hline SVR F0-F3 & $€ 56$ & Cicchetti et al. PharmacoEconomics-Italian Research Article 2011;13(2):81-99 \\
\hline SVR F4 & $€ 56$ & Cicchetti et al. PharmacoEconomics-Italian Research Article 2011;13(2):81-99 \\
\hline F0 & $€ 100$ & $\begin{array}{l}\text { Ruggeri et al. Farmeconomia. Health Economics and Therapeutic Pathways } \\
2014 ; 15(3): 61-70\end{array}$ \\
\hline
\end{tabular}

$F$ fibrosis, $S V R$ sustained virologic response

a The inputs for this table were based on the following sources and assumptions: Kondili et al. Hepatology 2019;70(S1):328A; Bayesian model, Cicchetti et al. PharmacoEconomics-Italian Research Article 2011;13(2):81-99; Regione Emilia-Romagna Aggiornamento Luglio 2019; Ruggeri et al. Farmeconomia. Health Economics and Therapeutic Pathways 2014;15(3):61-70; Dieguez et al. Hepatology 2016;64(S1):P59; Cacoub et al. Alimentary Pharmacology and Therapeutics 2018;47(1):123-128; Capri et al. Therapeutic Innovation and Regulatory Science 35(1):189-201; Kondili et al. Hepatology 2017;66:1814-1825

HCV population treated with 8 vs 12 weeks of $\mathrm{G} / \mathrm{P}$, assuming a fixed annual treatment budget of $€ 210$ million. This budget assumption was made so that 35,000 patients with HCV were treated annually in Italy, consistent with the projections from the Polaris Observatory [21]. The model also calculated any downstream health and economic benefits of expanding treatment capacity assuming all saved healthcare visits would be reallocated to treat more patients. This expansion in treatment capacity was calculated by dividing the total number of healthcare visits saved by the average number of healthcare visits for patients treated with 8 weeks of G/P.

\section{Outcomes}

The outcomes measured in this analysis were years on treatment, number of hepatologist visits, the difference in healthcare costs related to years on treatment and hepatologist visits 
between 12- and 8-week treatment with G/P, and any change in treatment capacity. In addition, this analysis also investigated outcomes associated with an increased treatment capacity. This included the number of cases of endstage liver disease (ESLD), liver-related death and HCC, treatment costs, costs for hepatic and extrahepatic complications, and overall healthcare costs.

\section{Analyses}

Clinical and economic outcomes with different treatment strategies were assessed under the same screening policy and healthcare budget. For patients without cirrhosis and with compensated cirrhosis, two strategies were compared: 12 weeks of treatment with $\mathrm{G} / \mathrm{P}$ and 8 weeks of treatment with $\mathrm{G} / \mathrm{P}$.

\section{RESULTS}

Patients treated with 12 weeks of G/P collectively spent 81,019 years on treatment compared with 54,013 years in patients treated with 8 weeks of G/P. Shorter treatment duration thus results in a reduction of $27,006(33.3 \%)$ years the patient population remains on treatment (Fig. 2a). The 8 -week vs 12 -week G/P treatment also resulted in 21,065 fewer hepatologist visits, corresponding to savings of $€ 386,215$, as patients had a total of 1,481,573 and 1,460,508 hepatologist visits on the 12- and 8-week G/P treatments, respectively (Fig. 2b). The resources saved, in terms of visits, would increase the capacity to treat $5064(1.4 \%)$ additional patients with 8 weeks of $\mathrm{G} / \mathrm{P}$, all with $\mathrm{CC}$.

The cost of treating these additional 5064 patients would result in a cumulative pharmaceutical cost of $€ 26,624,706$ by 2030 . However, this increased capacity to treat would also avoid a total of 893 liver-related deaths, 2257 cases of ESLD, and 1150 cases of HCC (Fig. 3). Accounting for the associated medical costs, 8 -week treatment would result in savings of $€ 56,910,575$ and $€ 39,312,021$ related to hepatic and extrahepatic complications, respectively. Overall, there would be a reduction in total healthcare costs of $€ 69,597,891$ with the
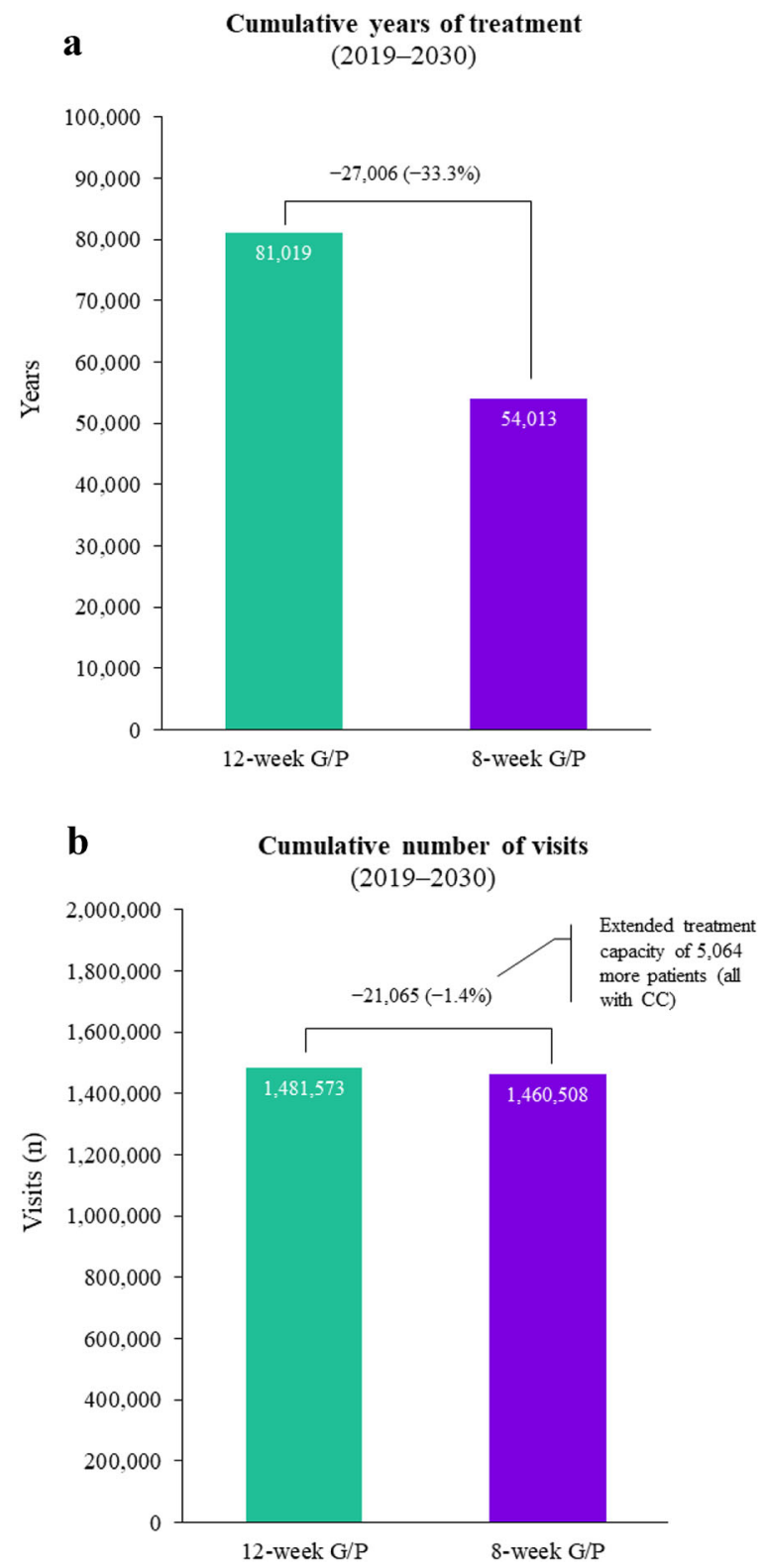

Fig. 2 a Cumulative years of treatment and $\mathbf{b}$ cumulative number of hepatologist visits from 2019 to 2030. CC compensated cirrhosis, G/P glecaprevir/pibrentasvir

shorter-duration treatment taking into account increased treatment capacity, reduced hepatologist visits, and reduced hepatic and extrahepatic complications. The cumulative healthcare costs by treatment duration are shown in Fig. 4 . 


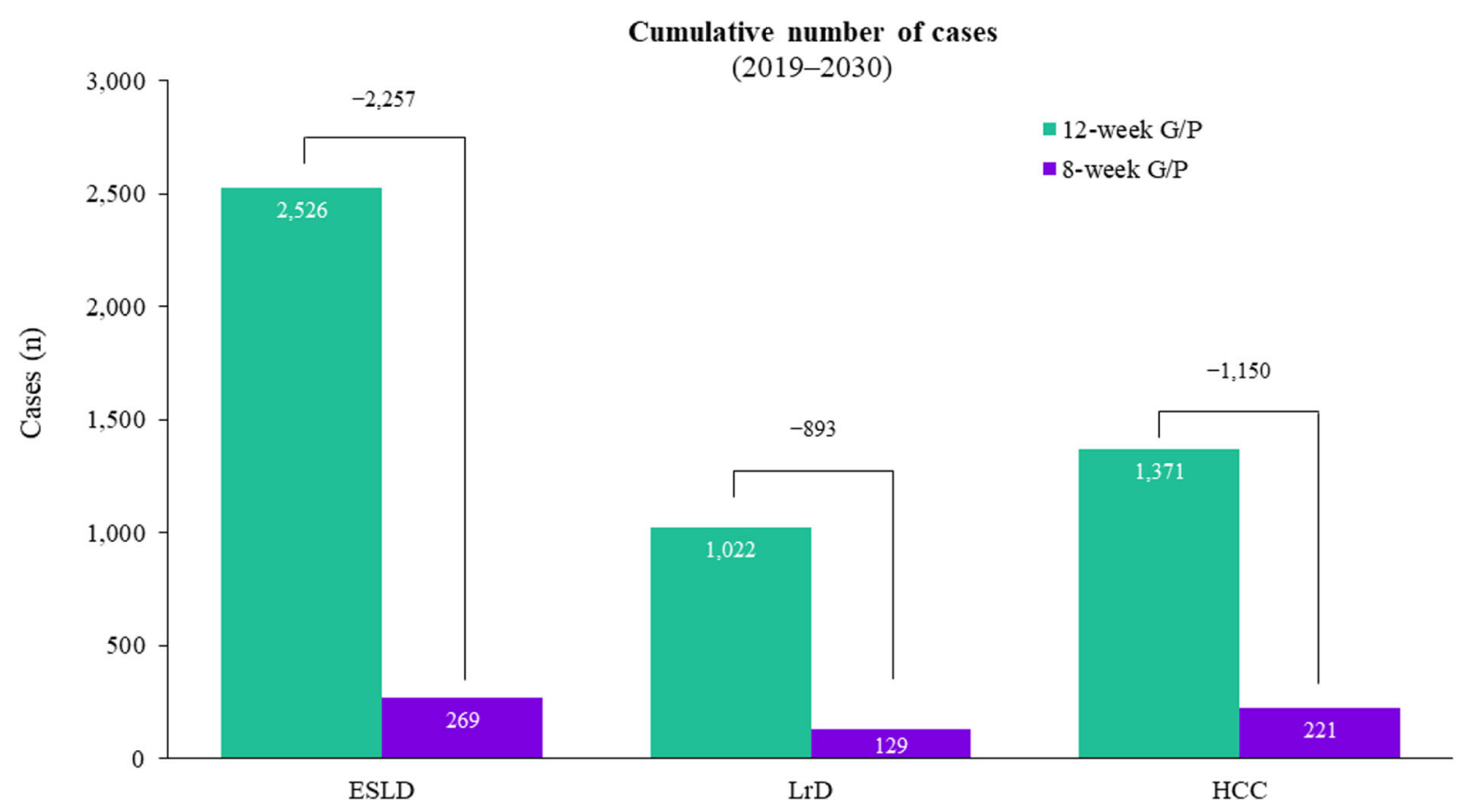

Fig. 3 Cumulative number of cases of end-stage liver disease, liver-related deaths and HCC after increasing treatment capacity; 8-week G/P treatment would increase treatment capacity by 5064 patients compared to 12 -week

\section{DISCUSSION}

The results of this analysis show that for Italy, 8-week treatment with G/P resulted in less time on treatment and fewer hepatologist visits, leading to an increase in the number of patients who could be treated and an overall decrease in healthcare costs compared with the 12-week $\mathrm{G} / \mathrm{P}$ duration. This suggests that 8 -week G/P treatment could lead to a simplified treatment pathway that provides greater benefits to patients and the healthcare system, as well as saving costs through reduced hepatic and extrahepatic complications.

Increasing the capacity to treat can reduce the number of patients with HCV progressing to more advanced liver disease and developing both hepatic and extrahepatic complications $[22,23]$. The country-specific model described in this study showed that for Italy, the increased treatment capacity of 5064 patients related to 8 -week treatment with G/P resulted in a reduction in cases of ESLD, liver-related deaths, and
G/P treatment. ESLD end-stage liver disease, G/P glecaprevir/pibrentasvir, HCC hepatocellular carcinoma, LrD liver-related death, $n$ number

HCC. In turn, the lower numbers of cases led to cost savings related to hepatic and extrahepatic complications of $€ 96,222,596$. In addition, the benefits of a shorter treatment duration may lead to further healthcare savings through reduced management of adverse events and concomitant medications, which were not quantified in the present analysis. Similar results were observed in other analyses showing that shorter-duration treatment can increase the number of patients who can be treated and decrease future healthcare expenditures related to HCV complications [22, 24]. In this study, the increased treatment capacity led to an increase in treatment costs; however, the results also suggest that the savings made by reducing the number of HCV-related complications can be higher than the additional treatment costs, resulting in overall cost savings of $€ 69,597,891$. It is important to note that the majority of the economic benefits of treating $\mathrm{HCV}$ are not immediate; in order to project the real benefits of expanding HCV treatment, a long-term perspective must be taken $[25,26]$. 


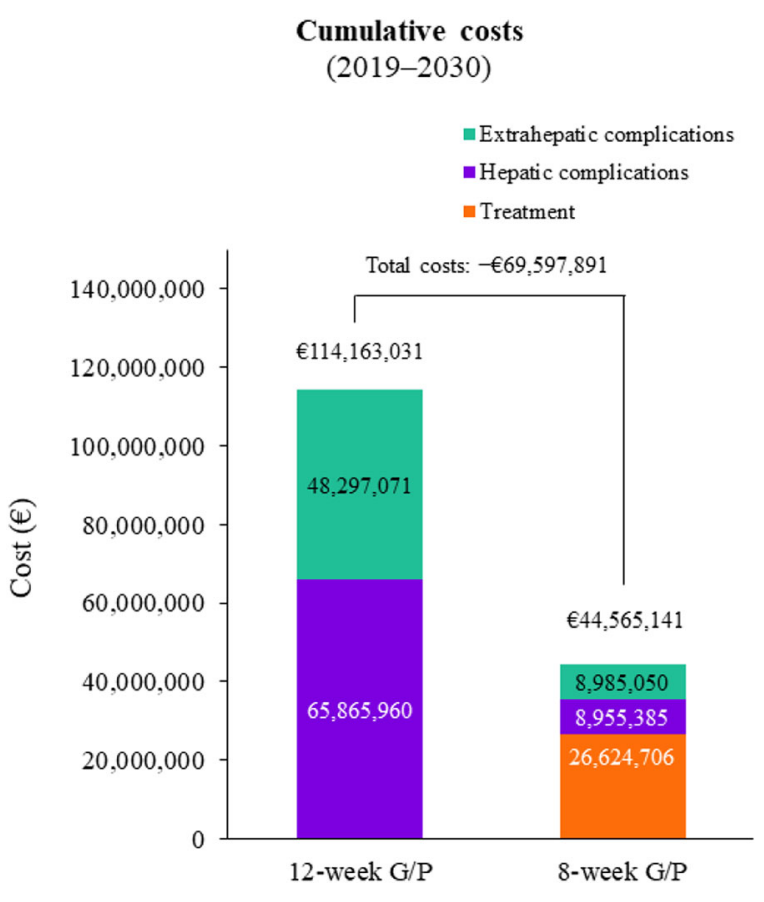

Fig. 4 Cumulative costs associated with an increased treatment capacity; 8-week G/P treatment would increase treatment capacity by 5064 patients compared to 12 -week G/P treatment. G/P glecaprevir/pibrentasvir

Many countries, such as Italy, have fixed healthcare budgets within which there are specific budgets allocated to the treatment of HCV [27]. The reduction in HCRU as well as the cost savings observed with 8-week G/P treatment in this analysis suggest that shorter-duration treatment has the potential to increase the capacity to treat more patients. The ability to increase treatment capacity is often restricted by countries' budget constraints or the availability of specialists to treat patients, which can lead to treatment being provided to only the sickest patients [22]. However, restricting the number of patients treated limits disease reduction and consequently elimination $[22,24]$. To accelerate $\mathrm{HCV}$ elimination, treatment capacity must be increased [22]. It is also possible that the costs and healthcare resources saved with a shorterduration treatment could be used to overcome the barriers to HCV elimination targets in Italy by initiating new, tailored programs aimed to engage and treat high-risk populations to increase HCV screening and linkage to care.
Shorter treatment duration could be particularly important given the restrictions placed on healthcare resources due to COVID-19, such as the availability of screening, diagnosis, and clinical care, as well as the economic impact of the pandemic, which will likely reduce access to care $[28,29]$; additionally, fewer healthcare visits as a result of a shorter treatment may be associated with less exposure to COVID-19 and other diseases, a benefit not quantified in the current study. Furthermore, the loss of progress towards HCV elimination in Italy before COVID-19 led to the implementation of a law enacted by the Italian Government in February 2020 to conduct graduated birth cohort screening for hepatitis; however, as a result of COVID-19 this has been delayed as of May 2020 [10]. Additionally, the average weekly treatment starts have reduced by more than $88 \%$ compared with 2018 [10]. This illustrates the already strained plans for HCV elimination, and the detrimental impact that further delays due to COVID-19 will likely have [10]. One model predicts that the downstream consequences from a 1-year delay in HCV elimination programs could result in 72,300 extra liver-related deaths and 44,800 extra liver cancer cases globally over the next 10 years [10]. This is supported by another model that shows that in Italy there is a progressive increase in the number of advanced liver disease cases and deaths as HCV treatment delays increase [29].

Currently, there are active projects in Italy that aim to help reach the HCV elimination goal, such as The HCV Network Sicily, a webbased model that includes physicians who manage and treat HCV, monitors patients' data, and shares optimized strategies with the goal of helping HCV elimination [12]. However, epidemiologic data for people who inject drugs (PWIDs), prisoners, migrants, and patients with human immunodeficiency virus/HCV coinfections are needed in order to find high-risk patients and provide tailored treatment programs [30]. It will become increasingly more difficult to find remaining untreated patients with HCV because of the asymptomatic nature of the early stages of disease and marginalization of high-risk populations [31]. The healthcare resources saved with a shorter-treatment 
duration could be used to find and treat these patient populations. Furthermore, a shortertreatment duration may bring greater value during and post COVID-19, through the saving of healthcare resources which are likely scarcer during the pandemic.

There are a few limitations of this study. The transition probabilities and costs were obtained from estimates in the literature, and actual values for these may differ across other settings and patient subgroups; the model did not account for $\mathrm{HCV}$ transmission, reinfection, treatment compliance, re-treatment, or additional factors related to chronic HCV infection; and results are projected and may differ from those observed in the real world. Also, the differences in healthcare visits between 8- and 12-week treatment with G/P may vary across regions and real-world treatment practices. PMOS data were used in this study to infer this difference; however, further studies are needed to confirm this.

\section{CONCLUSION}

Comparisons between 8- and 12-week G/P treatment show that 8-week treatment can lead to greater patient benefits and reduced HCRU. The resource savings, in terms of healthcare visits, with 8-week G/P treatment have the potential to increase treatment capacity within a given treatment budget and lead to downstream health benefits and cost savings. In addition, the 8-week G/P treatment duration could lead to a simplified treatment path for nonspecialist treatment, in turn increasing the number of patients treated. Given these benefits, 8-week G/P treatment can further support current efforts to achieve HCV elimination targets in Italy.

\section{ACKNOWLEDGEMENTS}

AbbVie contributed to the study design and participated in the collection, analysis, and interpretation of the data and in the writing, reviewing, and approval of the manuscript. No honoraria or payments were made for authorship. Glecaprevir was identified by AbbVie and Enanta.

Funding. AbbVie sponsored the study and funded the journal's Rapid Service Fee.

Medical Writing Assistance. Medical writing support was provided by Annie Massa, MBiolSci, and Laura Whiteley, PhD, of Fishawack Communications, Ltd; funded by AbbVie.

Authorship. All named authors meet the International Committee of Medical Journal Editors (ICMJE) criteria for authorship for this article, take responsibility for the integrity of the work as a whole, and have given their approval for this version to be published.

Author Contributions. All authors had access to relevant data and participated in the writing, review, and approval of the manuscript. Massimo Andreoni, Giovanni Di Perri, Marcello Persico, Andrea Marcellusi, Olivier Ethgen, Yuri Sanchez Gonzalez, Mark Bondin, Zhenzhen Zhang, Antonella De Michina, Rocco Cosimo Damiano Merolla, and Antonio Craxì all contributed to study concept and design; acquisition of data; analysis and interpretation of data; drafting of the manuscript; and critical revision of the manuscript for important intellectual content.

Disclosures. Massimo Andreoni: Board member of AbbVie, Gilead Sciences, Merck Sharp \& Dohme, and ViiV Healthcare. Speaker fees from Bristol-Myers Squibb, Gilead Sciences, and Janssen-Cilag, and grants from Merck Sharp \& Dohme. Travel/meeting expenses from AbbVie and Merck Sharp \& Dohme. Giovanni Di Perri, Andrea Marcellusi, Antonio Craxì: Have nothing to disclose. Marcello Persico: Consultant for Gilead, MSD, and AbbVie. Olivier Ethgen: Owns SERFAN Innovation and is a consultant for AbbVie. Yuri Sanchez Gonzalez, Mark Bondin, Zhenzhen Zhang, Antonella De Michina, Rocco Cosimo Damiano Merolla: Employees of AbbVie and may own stocks and/ or options in the company. 
Compliance with Ethics Guidelines. This article is based on previously conducted studies. The PMOS studies included were performed in accordance with the Helsinki Declaration of 1964, and its later amendments, and all patients provided informed consent to participate.

Data Availability. AbbVie is committed to responsible data sharing regarding the clinical trials we sponsor. This includes access to anonymized, individual and trial-level data (analysis data sets), as well as other information (e.g., protocols and Clinical Study Reports), as long as the trials are not part of an ongoing or planned regulatory submission. This includes requests for clinical trial data for unlicensed products and indications. This clinical trial data can be requested by any qualified researchers who engage in rigorous, independent scientific research, and will be provided following review and approval of a research proposal and Statistical Analysis Plan (SAP) and execution of a Data Sharing Agreement (DSA). Data requests can be submitted at any time and the data will be accessible for 12 months, with possible extensions considered. For more information on the process, or to submit a request, visit the following link: https://www.abbvie.com/ourscience/clinical-trials/clinical-trials-data-andinformation-sharing/data-and-informationsharing-with-qualified-researchers.html.

Open Access. This article is licensed under a Creative Commons Attribution-NonCommercial 4.0 International License, which permits any non-commercial use, sharing, adaptation, distribution and reproduction in any medium or format, as long as you give appropriate credit to the original author(s) and the source, provide a link to the Creative Commons licence, and indicate if changes were made. The images or other third party material in this article are included in the article's Creative Commons licence, unless indicated otherwise in a credit line to the material. If material is not included in the article's Creative Commons licence and your intended use is not permitted by statutory regulation or exceeds the permitted use, you will need to obtain permission directly from the copyright holder. To view a copy of this licence, visit http://creativecommons.org/licenses/by$\mathrm{nc} / 4.0 /$.

\section{REFERENCES}

1. World Health Organization. Global hepatitis report. 2017. http://apps.who.int/iris/bitstream/10665/ 255016/1/9789241565455-eng.pdf. Accessed 1 Nov 2020.

2. Pawlotsky J-M, Negro F, Aghemo A, et al. EASL recommendations on treatment of hepatitis C. J Hepatol. 2018;69(2):461-511. https://doi.org/10. 1016/j.jhep.2018.03.026.

3. Sandmann L, Schulte B, Manns MP, Maasoumy B. Treatment of chronic hepatitis C: efficacy, side effects and complications. Visc Med. 2019;35(3): 161-70. https://doi.org/10.1159/000500963.

4. AbbVie. Maviret (glecaprevir/pibrentasvir) summary of product characteristics. 2020. https://www. ema.europa.eu/en/documents/productinformation/maviret-epar-product-information_en. pdf. Accessed Mar 2020.

5. AbbVie. Mavyret (glecaprevir/pibrentasvir) US prescribing information. 2019. https://www. accessdata.fda.gov/drugsatfda_docs/label/2019/ 209394s008lbl.pdf. Accessed Mar 2020.

6. Brown RS Jr, Buti M, Rodrigues L, et al. Glecaprevir/ pibrentasvir for 8 weeks in treatment-naive patients with chronic HCV genotypes 1-6 and compensated cirrhosis: the EXPEDITION-8 trial. J Hepatol. 2020;72(3):441-9. https://doi.org/10.1016/j.jhep. 2019.10.020.

7. World Health Organization. Progress report on access to hepatitis C treatment. 2018. https://apps. who.int/iris/bitstream/handle/10665/260445/ WHO-CDS-HIV-18.4-eng.pdf;jsessionid=AC7402A DBBC3BA2404E5DF4768BE7F9B? sequence $=1$. Accessed Mar 2020.

8. Razavi H, Gonzalez YS, Yuen C, Cornberg M. Global timing of hepatitis $C$ virus elimination in high-income countries. Liver Int. 2020;40(3):522-9. https://doi.org/10.1111/liv.14324.

9. Wingrove C, Ferrier L, James C, Wang S. The impact of COVID-19 on hepatitis elimination. Lancet Gastroenterol Hepatol. 2020;5(9):792-4. https:// doi.org/10.1016/S2468-1253(20)30238-7.

10. Blach S, Kondili LA, Aghemo A, et al. Impact of COVID-19 on global hepatitis C elimination efforts. 
J Hepatol. 2020. https://doi.org/10.1016/j.jhep. 2020.07.042.

11. Kondili LA, Gamkrelidze I, Blach S, et al. Optimization of hepatitis $C$ virus screening strategies by birth cohort in Italy. Liver Int. 2020;40(7):1545-55. https://doi.org/10.1111/liv.14408.

12. Andreone P, Di Marco V, Gaeta GB, Fagiuoli S, Vukotic R, Craxi A. Current and forthcoming perspectives in linkage to care of hepatitis $C$ virus infection: assessment of an Italian focus group. Dig Liver Dis. 2019;51(7):915-21. https://doi.org/10. 1016/j.dld.2019.03.033.

13. Croce D, Bonfanti M, Restelli U. Financial and feasibility implications of the treatment of hepatitis $\mathrm{C}$ virus in Italy: scenarios and perspectives. Clinicoecon Outcomes Res. 2016;8(377-85):8. https:// doi.org/10.2147/CEOR.S106769.

14. Sangiorgi D, Perrone V, Buda S, et al. Epidemiology, patient profile, and health care resource use for hepatitis C in Italy. Clinicoecon Outcomes Res. 2017;9(609-16):9. https://doi.org/10.2147/CEOR. S136456.

15. Ethgen O, Gonzalez YS, Jeanblanc G, Duguet A, Misurski D, Juday T. Public health impact of comprehensive hepatitis $\mathrm{C}$ screening and treatment in the French baby-boomer population. J Med Econ. 2017;20(2):162-70. https://doi.org/10.1080/1369 6998.2016.1232725.

16. Lampertico P, Flisiak R, Marques N, et al. Real-world clinical practice outcomes in hepatitis C-infected patients with psychiatric and substance use disorders treated with glecaprevir/pibrentasvir for 8 or 12 weeks: a pooled analysis across 9 countries. EASL 2020 Poster THU440. J Hepatol. 2020;73(Suppl1): S358-9. https://doi.org/10.1016/S0168-8278(20)31 212-5.

17. Rizzardini G, Gschwantler M, Bourgeois S, et al. Real-world outcomes in patients with chronic hepatitis $C$ virus infection and substance use disorders treated with glecaprevir/pibrentasvir for 8 weeks: a pooled analysis of multinational postmarketing observational studies. AASLD 2020 Poster 0929. Hepatology. 2020;72(Suppl1):568A. https://doi.org/10.1002/hep.31579.

18. Aghemo A, Bourgeois S, Gschwantler M, et al. Realworld health care resource utilization and quality of life with glecaprevir/pibrentasvir treatment: a pooled analysis from post-marketing observational studies. EASL 2019 Poster THU-112. J Hepatol. 2019;70(Suppl1):e207. https://doi.org/10.1016/S01 68-8278(19)30203-X.

19. Lampertico P, Peck-Radosavljevic M, Bondin M, et al. Addressing barriers to hepatitis $\mathrm{C}$ virus (HCV) elimination: real-world outcomes in historically underserved patients with chronic HCV infection treated with glecaprevir/pibrentasvir. AASLD 2019 Poster 1583. Hepatology. 2019;70(Suppl1): 954A-5A. https://doi.org/10.1002/hep.30941.

20. Lampertico P, Peck-Radosavljevic M, Bondin M, et al. Real-world effectiveness and safety of glecaprevir plus pibrentasvir in HCV: a multi-country analysis of post-marketing observational studies. EASL 2019 Poster THU-151. J Hepatol. 2019; 70(Suppl1):e228. https://doi.org/10.1016/S0168-82 78(19)30203-X.

21. Polaris Observatory. Last updated 2020. https:// cdafound.org/dashboard/polaris/dashboard.html. Accessed Sep 2020.

22. Sbarigia U, Wirth D, Van Nuys K, et al. Economic study of the value of expanding $\mathrm{HCV}$ treatment capacity in Germany. BMJ Open Gastroenterol. 2017;4(1):e000130. https://doi.org/10.1136/ bmjgast-2016-000130.

23. Moreno GA, Wang A, González YS, et al. Value of comprehensive HCV treatment among vulnerable, high-risk populations. Value Health. 2017;20(6): 736-44. https://doi.org/10.1016/j.jval.2017.01.015.

24. Tenner L, Melhado T, Bobadilla R, Turner B, Morgan R. The cost of cure: barriers to access for hepatitis $\mathrm{C}$ virus treatment in South Texas. J Oncol Pract. 2019;15(2):61-3.

25. Cipriano LE, Goldhaber-Fiebert JD. Population health and cost-effectiveness implications of a "treat all" recommendation for HCV: a review of the model-based evidence. MDM Policy Pract. 2018. https://doi.org/10.1177/2381468318776634.

26. Rattay T, Dumont IP, Heinzow HS, Hutton DW. Cost-effectiveness of access expansion to treatment of hepatitis $\mathrm{C}$ virus infection through primary care providers. Gastroenterology. 2017;153(6):1531-43. https://doi.org/10.1053/j.gastro.2017.10.016.

27. Chou JW, Silverstein AR, Goldman DP. Short-term budget affordability of hepatitis $C$ treatments for state Medicaid programs. BMC Health Serv Res. 2019;19(1):140. https://doi.org/10.1186/s12913019-3956-X.

28. Pawlotsky JM. COVID-19 and the liver-related deaths to come. Nat Rev Gastroenterol Hepatol. 2020. https://doi.org/10.1038/s41575-020-0328210.1038/s41575-020-0328-2.

29. Kondili LA, Marcellusi A, Ryder S, Craxi A. Will the COVID-19 pandemic affect HCV disease burden? Dig Liver Dis. 2020. https://doi.org/10.1016/j.dld. 2020.05.04010.1016/j.dld.2020.05.040. 
30. Gardini I, Bartoli M, Conforti M, Mennini FS, Marcellusi A. Estimation of the number of HCVpositive patients in Italy. PLoS One. 2019;14(10): e0223668. https://doi.org/10.1371/journal.pone. 0223668.
31. Marascio N, Liberto M, Barreca G, et al. Update on epidemiology of HCV in Italy: focus on the Calabria Region. BMC Infect Dis. 2014. https://doi.org/10. 1186/1471-2334-14-S5-S2. 